\title{
The Efficacy of Computer-Mediated Feedback in Improving L2 Speaking: A Systematic Review
}

\author{
Wenrui Zhang \\ Department of English, The Chinese University of Hong Kong, Hong Kong SAR, China
}

\begin{abstract}
Recent trends in computer-mediated communication (CMC) have led to a proliferation of studies investigating the effect of computer-mediated feedback (CMF). The present systematic review aimed to explore the role of linguistic, contextual, and individual factors in mediating the impact of CMF on second language (L2) speaking performance. A literature search located 16 relevant empirical studies for the final analysis. Each study was coded for linguistic, contextual, and individual characteristics. First, CMF was theoretically conceptualized as an instructional input, a dialogic process, and an internal process based on theoretical underpinnings. Correspondingly, CMF was analyzed under the influence of 1) linguistic factors including feedback type, the linguistic focus of CMF, and the timing of CMF, 2) contextual factors including the feedback source and the task type, and 3) individual factors including individual differences and learners' proficiency levels. The implication of the study was twofold. Theoretically, this study not only provided a multi-dimension view towards the effect of CMF in developing L2 oral proficiency but also shed new light on the interrelations between these identified factors. Pedagogically, teachers were encouraged to take advantage of CMC technologies to enhance the effectiveness of CMF as well as considering learners' uniqueness. Suggestions for future research were also provided.
\end{abstract}

Index Terms - computer-mediated feedback (CMF), L2 speaking, linguistic factors, contextual factors, individual factors

\section{BACKGROUND}

The COVID-19 pandemic in 2020 has triggered a huge amount of computer-mediated communication (CMC) inquiry in the field of second language acquisition (SLA). CMC refers to communication via computers between individuals (Herring, 1996). The dynamic nature of CMC is believed to be four-fold: temporality, anonymity, modality, and spatiality (Smith et al., 2003). These features highlight the effectiveness of CMC in facilitating second language (L2) development that cannot be provided by the traditional face-to-face environment. From the perspectives of contextual and linguistic factors, CMC creates and supports a flexible social context for authentic communication while drawing learners' attention to linguistic input (Heift \& Rimrott, 2008;Kim, 2014;Young \& Wang, 2014). From the perspectives of learners' individual differences, CMC can not only strengthen learners' motivation and self-confidence but also reduce anxiety (Kelm, 1992;Kern, 1995). Thus, the importance of CMC in L2 learning is indisputable.

Feedback is a major contributor to successful language learning (Hattie \& Timperley, 2007). Broadly speaking, feedback takes the form of suggestions or comments for improvement that are provided through recognizing the quality of performance (Sadler, 1989). This kind of feedback assists learners in identifying their learning strengths and weaknesses, and improving their understanding and performance (Sadler, 1989). Narrowly speaking, in the context of L2 teaching, the feedback that learners receive mostly refers to corrective feedback (CF), i.e., the feedback on oral or written linguistic errors made by L2 learners (Sheen \& Ellis, 2011). As Schmidt (1990) states in the noticing hypothesis, i.e., the intake for learning comes from learners' notice in input, CF could help learners notice the gap between their interlanguage and the target L2 form by addressing learners' erroneous utterances (Lochtman, 2002). In this study, feedback ranges from both formal and structured comments to specific CF on learners' speech (Yu et al., 2018).

Recent technological advancements have offered the opportunities of utilizing CMC technologies to provide feedback on the speaking performance of L2 learners, which can lead learners towards improved performance (Gu et al., 2021). This kind of feedback, driven by CMC technologies, is defined as computer-mediated feedback (CMF) (Bahari, 2021). Evidence from a number of experimental and meta-analyses studies has established that CMF benefits L2 learning (Sagarra \& Abbuhl, 2013; Young \& Wang, 2014;Ziegler, 2016). For instance, CMF is effective in enhancing achievement and engagement (Gašević et al., 2016), facilitating collaborative learning (Rassaei, 2017;Yu \& Lee, 2016), creating a cosy atmosphere of learning (Cornillie et al., 2012), improving writing skills (Bitchener \& Ferris, 2012), developing oral proficiency (Lyster et al., 2013;Sagarra \& Abbuhl, 2013), and providing real-time error correction (Kato et al., 2016). These potential advantages of CMF emphasized the importance and need to expand studies on using CMF to facilitate L2 learning (Tabrizi, 2021).

Although studies have recognized the significance of CMF in the development of L2, there are still some research gaps that exist. On the one hand, comparing to studies investigate written competence, relatively few studies have analyzed the impact of CMF on L2 oral production (AbuSeileek \& Abualsha'r, 2014;Shintani, 2016). Accordingly, the present study systematically reviews the literature published in the last decade (2012-2021) exploring the effect of CMF 
on L2 speaking proficiency. On the other hand, the existing literature has predominantly concentrated on the linguistic aspects of CMF such as the feedback type (e.g., recasts, prompt, comment), the linguistic focus of L2 speaking (e.g., pronunciation, grammar, vocabulary, fluency, accuracy), and feedback timing (e.g., immediate, delayed) (Andújar-Vaca \& Cruz-Martínez, 2017;Fang et al., 2021;Rassaei, 2017, 2019). However, the effect of CMF not only depends on its linguistic features (Lyster \& Saito, 2010;Pawlak, 2014), but also subjects to multiple 1) contextual characteristics such as task type (Gurzynski-Weiss \& Révész, 2012), feedback source (Carless, 2016), and 2) individual variables such as working memory (Sagarra \& Abbuhl, 2013), proficiency level (Mackey \& Philp, 1998), motivation (Uzum, 2011), anxiety (Sheen, 2008). Unfortunately, the role of contextual factors and individual differences has received scant scholarly attention (Yu et al., 2018). Therefore, to fill this gap in the CMF literature, this review takes linguistic, contextual, and individual factors into consideration. Specifically, this study aims to discover new developments and provide directions for future research in exploring the effectiveness of CMF with the following research question: How do linguistic, contextual, and individual factors impact CMF in developing L2 oral proficiency?

\section{THEORETICAL FOUNDATIONS}

This systematic review was underpinned by three interrelated cognitive theories of SLA: output hypothesis (Swain, 1993), interaction hypothesis (Long, 1996), and noticing hypothesis (Schmidt, 1994).

Firstly, developed by Swain (1993), the output hypothesis states that learners learn new linguistic knowledge by noticing the gap between their utterances and the target form, which enables them to be aware of it and modify their output by receiving feedback containing implicit or explicit input about the linguistic errors (Sheen \& Ellis, 2011). Therefore, CMF can be conceptualized as an instructional input that intends to help learners process and repair their linguistic errors ( $\mathrm{Yu}$ et al., 2018). The efficiency of this instructional input is largely dependent on linguistic factors, e.g., feedback type, linguistic focus, and timing (Lyster \& Ranta, 1997).

Secondly, according to the interaction hypothesis, L2 proficiency is developed by interaction and communication (Long, 1996). Similarly, the sociocultural perspective views feedback as a dialogic process whereby learners develop their L2 proficiency through interacting and cooperating with an expert (e.g., an instructor, a more capable peer, and a computer system) (Sheen \& Ellis, 2011). Both of the two aforementioned perspectives posit the importance of the external environment the learners are exposed to, e.g., the feedback provider and the feedback type (Ellis, 2010a). In this sense, CMF can be regarded as a dialogic process.

Thirdly, the noticing hypothesis argues that L2 learners cannot transfer input into intake unless they can consciously notice the input (Schmidt, 1994). Likewise, researchers from social constructivism perspectives have conceptualized feedback as an internal process, through which learners engage in processing, generating, and reacting to feedback (Ellis, 2010b). The ability of noticing is mediated by learner internal factors, e.g., working memory, anxiety level, and proficiency level (Pawlak, 2014). Thus, CMF can be defined as an internal process.

Taken together, CMF can be defined as an instructional input, a dialogical process and an internal process, whose efficacy is regulated by linguistic, contextual, and individual factors respectively.

\section{METHOD}

This systematic review qualitatively analyzed 16 selected primary studies to provide a comprehensive as well as a rigorous overview of the efficacy of CMF on L2 speaking proficiency.

\section{A. Literature Search}

Efforts were made to conduct a meticulous and thorough literature search with the goal of providing a better understanding of how CMF facilitates L2 oral proficiency development and offering a comprehensive analysis of the latest peer-reviewed studies published from 2012 to 2021. The identified major terms include: 1) computer-mediated/ computer-assisted/ technology-based feedback; 2) speaking skill/ competence, oral proficiency; 3) second/ foreign language, L2, which were keywords used by primary studies in the area of education, linguistics, information technology, e-learning, computer science interdisciplinary, and psychology. Then, combinations of the key terms with appropriate Boolean operators ("AND" or "OR) were used to search eligible studies published in electronic databases of Wiley, ERIC (Education Resources Information Center), Scopus, Sage, EBSCOhost (Academic Search Premier), Taylor and Francis (Tandf), Web of Science (WOS), and Emerald.

\section{B. Study Selection}

More than 300 studies relating to CMF and L2 oral proficiency were identified through the retrieval process. The following inclusion and exclusion criteria were applied to determine relevance to the proposed research questions.

Inclusion criteria

1. The study identified its participants as L2 learners without learning disabilities or language impairments.

2. The study provided feedback using different digital platforms: computer, mobile, website.

3. The study accessed L2 oral proficiency including accuracy, fluency, and speaking strategy.

4. The study was published in English.

Exclusion criteria 
1. The duplicate studies were removed to avoid double-counting.

2. The non-empirical studies such as review articles or editorial.

3. The study did not report critical information for the present systematic review, e.g., the correlation between CMF and speaking skills.

Besides, a snowballing strategy was employed, i.e., references in the selected studies and meta-analyses on similar topics (Bahari, 2021; Young \& Wang, 2014;Yu et al., 2018) were used to identify potentially qualified studies and further ensure a complete literature selection, resulting in 13 eligible studies. The Preferred Reporting Items for Systematic Reviews and Meta-Analyses (PRISMA) flow diagram (Fig. 1) illustrates the selection steps.
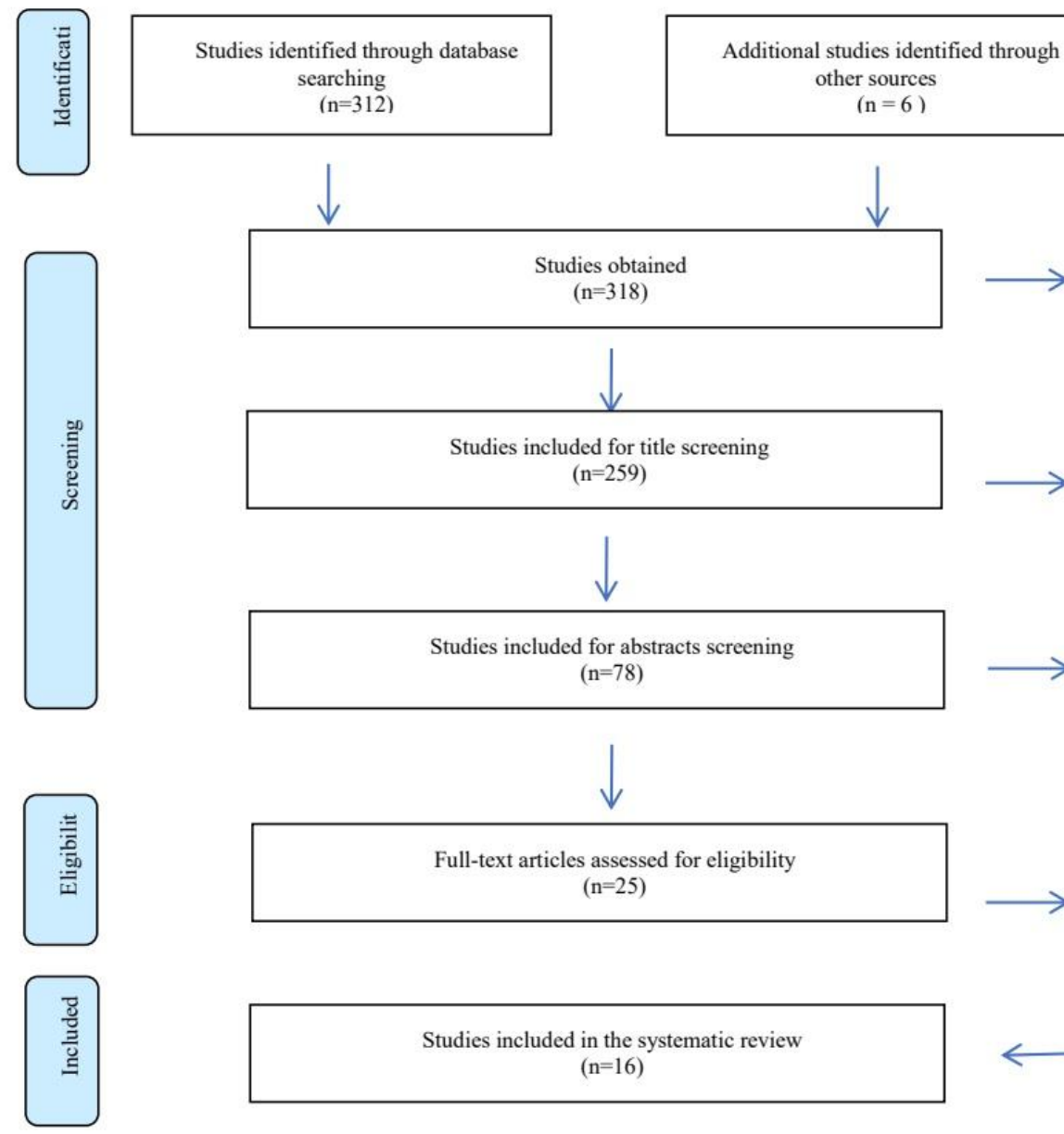

$(\mathrm{n}=318)$
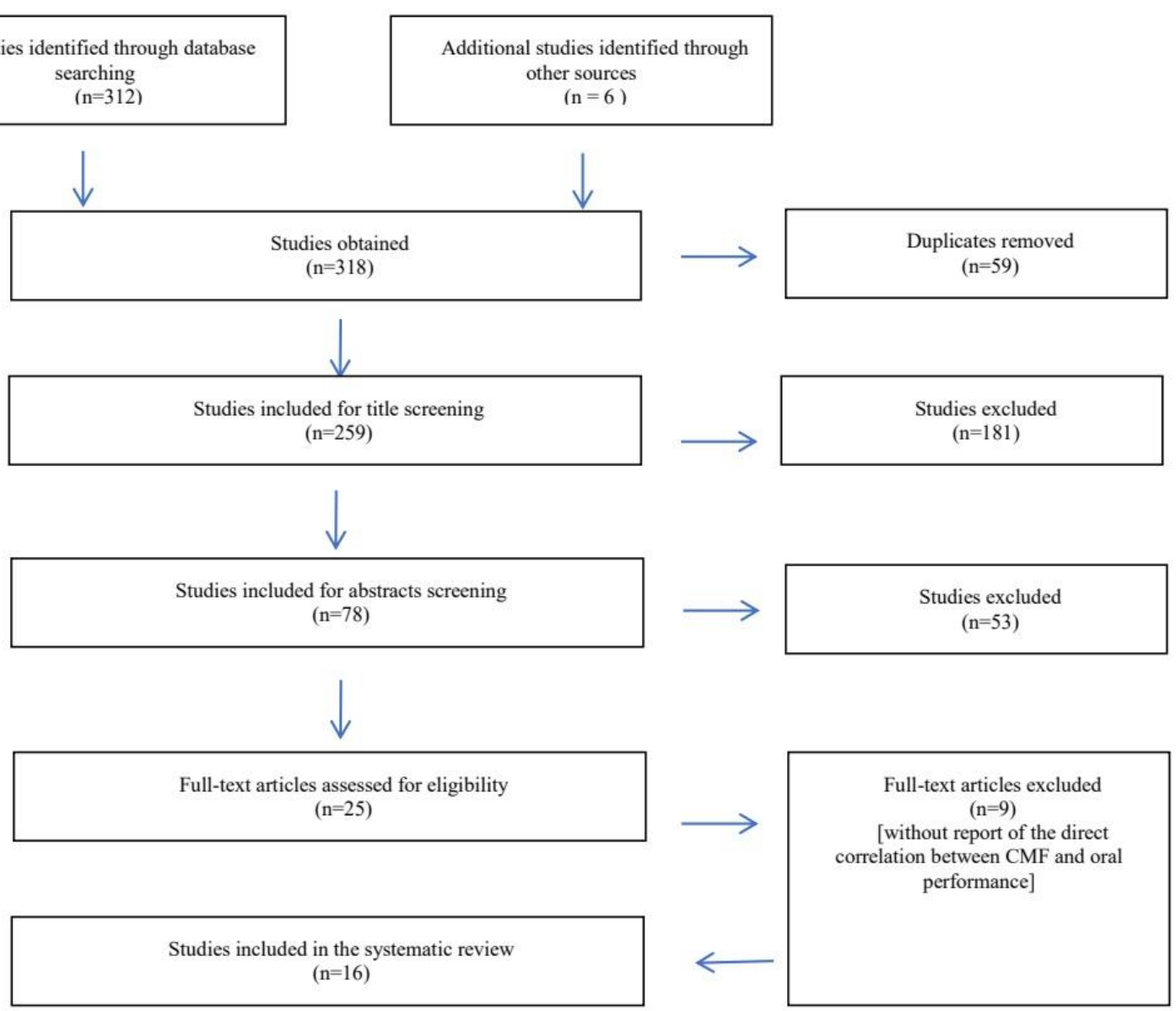

Studies included in the systematic review $(\mathrm{n}=16)$
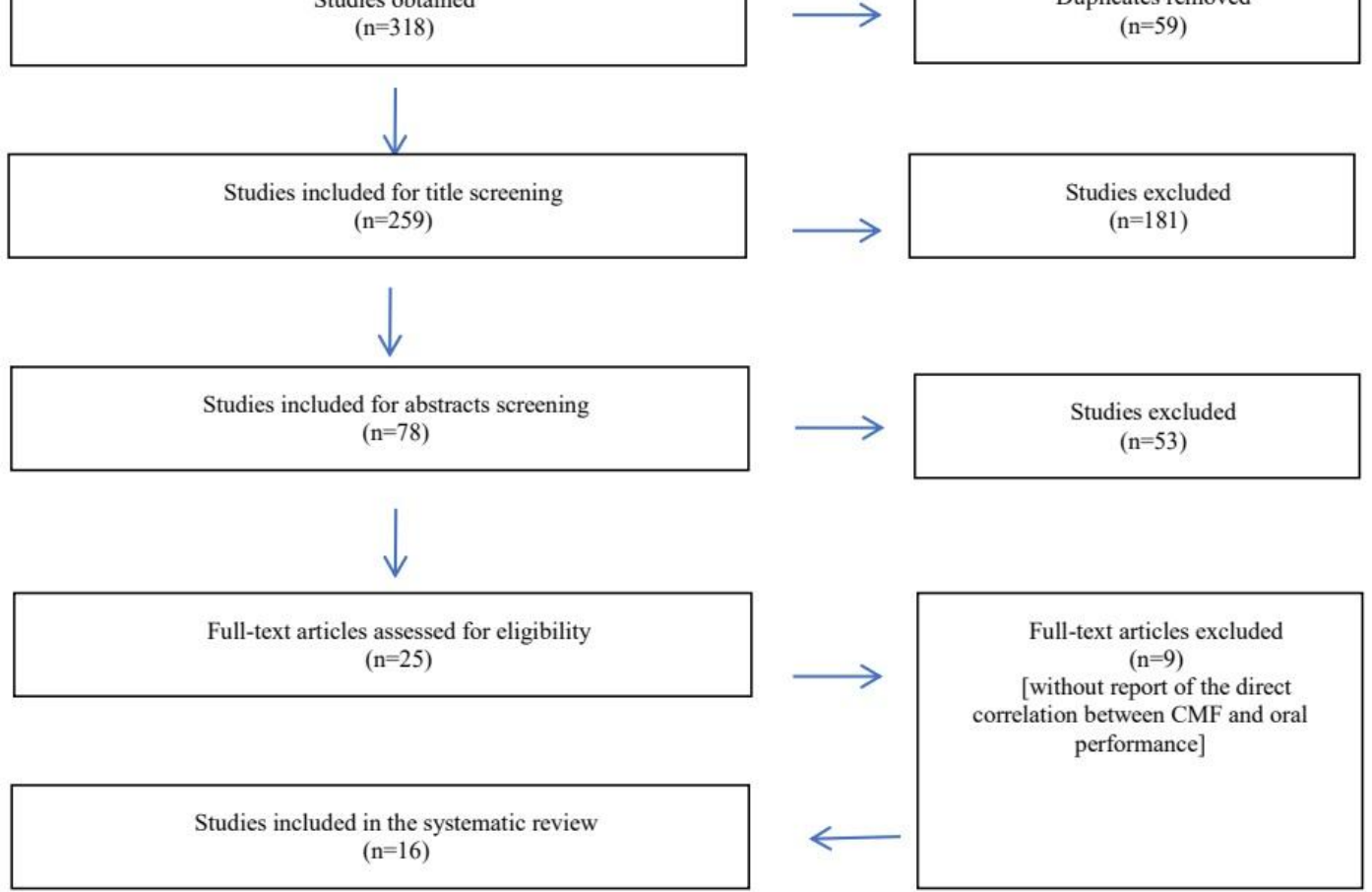

Figure 1. PRISMA Flow Diagram

\section{Data Analysis}

The data analysis comprised two steps. First, the basic information of reviewed studies was summarized in Appendix A accessing: 1) information about the author(s) and publication year; 2) sample size; 3) participants' portfolio including their gender, age, and L2 (Shin, 2020). Second, the characteristics of the primary studies were classified and summarized into three categories namely linguistic, contextual, and individual factors (Yu et al., 2018) (see Table 1). In total, thirteen subcategories were developed to better capture the effect of CMF on L2 oral proficiency development. Each selected study was analyzed using this coding schema.

TABLE 1

DATA ANALYSIS RESULT

\begin{tabular}{|l|l|l|}
\hline Themes & Subcategories & Codes \\
\hline \multirow{3}{*}{ Linguistic factor } & Feedback type & $\begin{array}{l}\text { CF (including recast, explicit correction, clarification request, elicitation, } \\
\text { metalinguistic feedback, and repetition), score, comment, colour, wave-form graph }\end{array}$ \\
\cline { 2 - 3 } & Linguistic focus & $\begin{array}{l}\text { Pronunciation, grammar, vocabulary, fluency, comprehension, accuracy, tone, } \\
\text { coherence, speaking skills }\end{array}$ \\
\cline { 2 - 3 } & Feedback timing & Immediate, delayed \\
\hline Contextual factor & Task type & Focused, unfocused \\
\cline { 2 - 3 } & Feedback source & Instructor, peer, computer system \\
\hline Individual factor & Individual differences & Working memory, anxiety, motivation \\
\cline { 2 - 3 } & Proficiency level & Advanced, intermediate, elementary, and beginner proficiency \\
\hline
\end{tabular}




\section{RESULTS}

The reviewed articles were discussed based on CMF's diverse conceptualizations: an instructional input, a dialogical process and an internal process, which are influenced by linguistic, contextual, and individual factors respectively.

\section{A. CMF as an Instructional Input}

Table 2 displays the reported linguistic factors that influence the effectiveness of CMF on L2 speaking performance.

TABLE 2

LINGUISTIC FACTORS

\begin{tabular}{|c|c|c|c|}
\hline Study & Feedback type & Linguistic focus & Feedback timing \\
\hline Ahn and Lee (2016) & Elicitation & Pronunciation, vocabulary & Immediate \\
\hline $\begin{array}{l}\text { Andújar-Vaca and Cruz-Martínez } \\
(2017)\end{array}$ & Recast, elicitation & $\begin{array}{l}\text { Pronunciation, grammar, vocabulary, } \\
\text { fluency, comprehension }\end{array}$ & Immediate \& Delayed \\
\hline Bryfonski and Ma (2020) & $\begin{array}{l}\text { Recast, metalinguistic } \\
\text { feedback }\end{array}$ & Tone & Immediate \\
\hline de Vries et al. (2015) & $\mathrm{CF}$ & Grammar & Immediate \\
\hline de Vries et al. (2016) & $\mathrm{CF}$ & Grammar & Immediate \\
\hline Ebadijalal and Yousofi (2021) & $\mathrm{CF}$ & $\begin{array}{l}\text { Pronunciation, grammar, accuracy, } \\
\text { fluency, coherence }\end{array}$ & Delayed \\
\hline Fang et al. (2021) & $\mathrm{CF}$ & $\begin{array}{l}\text { Vocabulary, fluency, accuracy, } \\
\text { comprehension }\end{array}$ & Immediate \& Delayed \\
\hline Gleason and Suvorov (2012) & Comment & Pronunciation, fluency, speaking skills & Delayed \\
\hline Gu et al. (2021) & $\begin{array}{l}\text { Score, colour, wave- } \\
\text { form graph }\end{array}$ & Fluency, pronunciation, vocabulary, & Delayed \\
\hline Martin and Valdivia (2017) & $\mathrm{CF}$ & Oral performance in general & Immediate \& Delayed \\
\hline Rassaei (2017) & Recast & $\begin{array}{l}\text { Accuracy of the target feature (the } \\
\text { definite article 'the') }\end{array}$ & Immediate \\
\hline Rassaei (2019) & Recast & $\begin{array}{l}\text { Accuracy of the target feature (the } \\
\text { articles ' } a \text { ' and 'the') }\end{array}$ & Immediate \\
\hline Sagarra and Abbuhl (2013) & Recast & $\begin{array}{l}\text { Accuracy of the target feature (noun- } \\
\text { adjective agreement) }\end{array}$ & Immediate \\
\hline Wu and Miller (2020) & Score, comment & Fluency, accuracy, pronunciation, & Immediate \\
\hline Yang et al. (2012) & $\mathrm{CF}$ & $\begin{array}{l}\text { Pronunciation, fluency, comprehension, } \\
\text { vocabulary, accuracy }\end{array}$ & Immediate \& Delayed \\
\hline Yu et al. (2016) & Comment & Oral performance in general & Immediate \\
\hline
\end{tabular}

\section{Feedback Type}

In the field of SLA, Lyster and Ranta (1997a) identified six types of corrective feedback, and from the most implicit one to the most explicit one they are: recasts, metalinguistic feedback, clarification requests, explicit corrections, repetitions, and elicitations. Among them, recasts (56\%) have been largely investigated by the reviewed studies, followed by prompts such as and elicitation (50\%) and metalinguistic feedback (44\%).

As Rassaei (2019) illustrated in his study about learners' interpretations of recasts, it is worthwhile and informative to study the $\mathrm{CF}$ perceptions of providers and receivers in order to evaluate the effectiveness of CF. With regard to providers' views of these feedback types, Bryfonski and Ma (2020) investigated the effects of explicit versus implicit $\mathrm{CF}$ on Mandarin tone acquisition. The instructor initially preferred metalinguistic feedback over recasts because metalinguistic could offer more explanations on the target feature. However, after the experiment, the instructor indicated the domination of recasts due to their ease of delivery. In the follow-up semi-structured interviews, the instructor commented that her perception of feedback type was associated with the time constraints of their classes and the proficiency level of the learners. This preference largely corroborated that of learners in Andújar-Vaca and CruzMartínez (2017) that learners also used recasts more frequently than elicitation to help their partners in oral production when they were engaged in peer interactions. From the receivers' perspective, there was a mismatch between learners' perceived and practical preference for CF in Bryfonski and Ma (2020)'s study. Students thought they wanted to receive metalinguistic feedback with detailed explanations, whereas in reality, they preferred recasts without interruption of their speaking. This is partially consonant with previous work done by Martin and Valdivia (2017) suggesting that learners rated explicit correction as the most effective strategy. Besides the perception of $\mathrm{CF}$, Gu et al. (2021) investigated learners' perceptions of the usefulness of automated feedback using the score, colour, and wave-form graph in facilitating the Speaking section of the TOEFL iBT test. The vast majority of participants acknowledged the helpfulness of these feedback types because of its construct relevance and its diagnostic nature. Another line of research has focused on L2 students' cognitive processing capacity which is closely related to the efficacy of feedback (Egi, 2010). Using stimulated recall interviews, a vast majority of the English as the foreign language (EFL) learners in the studies of Rassaei $(2017,2019)$ could successfully notice recasts as CF in computer-mediated instructional contexts, which guarantees the practicality of recasts. 


\section{Linguistic Focus of CMF}

According to the general proficiency speaking scale proposed by Hughes and Reed (2016), learners' speaking skills should be assessed in terms of comprehension, grammar, vocabulary, fluency, and pronunciation, which is also the case in the reviewed literature in this study. What stands out in Table 2 is the high rate of focus on pronunciation and accuracy (44\%). The linguistic features that also attracted academic attention among the reviewed studies are fluency (31\%), grammar $(25 \%)$, and vocabulary $(25 \%)$.

Andújar-Vaca and Cruz-Martínez (2017) reported 80 Spanish EFL learners' views toward the linguistic focus of CMF by statistically analyzing their LREs signals in their chat on Whatsapp. The results showed that correction of phonological errors was the most abundant, which might be explained by the fact that phonology is fundamental in English interaction (Yu et al., 2018). The least favored error type to be addressed was morphosyntactic. This finding largely coincides with Mackey et al. (2000)'s belief that students were more capable of identifying and recognising the phonological errors more accurately than morphosyntactic ones.

\section{Timing of $C M F$}

Timing serves as one of the most crucial mediators of the effectiveness of CMF (Goodman et al., 2004;Smits et al., 2008). An inspection of the data in Table 2 reveals that researchers examined the immediate CMF (81\%) more often than the delayed CMF (44\%).

Yang et al. (2012) surveyed 90 freshmen EFL learners at an Asian university to empirically test the effectiveness of voice over instant messaging, a web-based learning application, for enhancing learners' oral proficiency. All of the participants were regarded as the advanced English learners. In this study, both immediate and delayed feedback was provided by tutors. The result indicated that learners who received delayed feedback did not improve as significantly as those who received immediate feedback. Although the delayed feedback was detailed, learners might have already forgotten the types of mistakes they had made. Thus, it was arduous for those advanced learners to take advantage of corrections supplied by the delayed feedback. Similarly, Martin and Valdivia (2017) analyzed that immediate CF may interrupt the natural flow of speech and it may also undermine both the learners' confidence and increase their anxiety. This finding is contrary to that of Guadagnoli et al. (1996) who found that the learning outcome of the lowerintermediate learners was fostered by immediate feedback, whereas delayed feedback is more effective for advanced learners. This result may reflect differences in the criteria defining learners' language proficiency. However, this finding is partially consistent with a more recent study exploring the impact of feedback timing on learning online, which has suggested that there were no remarkable correlations between language proficiency and feedback timing (Smits et al., 2008).

\section{B. CMF as a Dialogical Process}

Table 3 presents the contextual factors of CMF in terms of feedback source, task type, and assessment task.

TABLE 3

CONTEXTUAL FACTORS

\begin{tabular}{|l|l|l|}
\hline Study & Feedback source & Task type \\
\hline Ahn and Lee (2016) & Computer & Unfocused \\
\hline Andújar-Vaca and Cruz-Martínez (2017) & Peers & Unfocused \\
\hline Bryfonski and Ma (2020) & Instructor & Focused \\
\hline de Vries et al. (2015) & Computer & Focused \\
\hline de Vries et al. (2016) & Computer & Focused \\
\hline Ebadijalal and Yousofi (2021) & Peers & Unfocused \\
\hline Fang et al. (2021) & Peers \& Computer & Unfocused \\
\hline Gleason and Suvorov (2012) & Peers \& Instructor & Unfocused \\
\hline Gu et al. (2021) & Computer & Unfocused \\
\hline Martin and Valdivia (2017) & Instructor & Unfocused \\
\hline Rassaei (2017) & Peers & Focused \\
\hline Rassaei (2019) & Instructor & Focused \\
\hline Sagarra and Abbuhl (2013) & Computer & Focused \\
\hline Wu and Miller (2020) & Peers & Unfocused \\
\hline Yang et al. (2012) & Instructor & Unfocused \\
\hline Yu et al. (2016) & Computer & Unfocused \\
\hline
\end{tabular}

\section{Feedback Source}

Although previous research has recognized the essence of feedback provided by instructors, peers, and computer systems, research has yet to systematically investigate the effect of feedback sources on speaking skills (van Ginkel et al., 2017). It can be seen from the data in Table 3 that the rates of these three feedback sources in the selected studies are almost equivalent: $44 \%$ of feedback was generated by computers automatically, $38 \%$ and $31 \%$ came from peers and instructors respectively.

Firstly, regarding the feedback provided by peers, Gleason and Suvorov (2012) addressed learner perceptions of CMF offered by both peers and instructors in aiding their oral skills. In the semi-structured interviews, learners 
expressed their desire to communicate with fellow classmates through an online platform. They believed such CMC technology to be reciprocal that allowed them to obtain peer feedback, and further promote learners to 1) reflect on their own oral performance, 2) exchange value and ideas, and 3) interact with their peers. More recently, Wu and Miller (2020) confirmed this result by collecting 25 Hong Kong learners' attitudes towards mobile-assisted peer feedback. They found that involving students in giving peer feedback not only transferred learners' identity from receivers relying on teacher feedback to producers and evaluators of knowledge but also engaged learners in a more socially equal atmosphere of speaking (Wu \& Miller, 2019). The result revealed learners' appreciation to offer and receive peer feedback, which allowed them to participate in speaking tasks fully and collaboratively. In addition, Ebadijalal and Yousofi (2021) also reported participants' positive attitudes towards peer feedback, perceiving it as an ideal substitution for instructor feedback. Nonetheless, some participants failed to recognize the advantages of peer feedback due to their lack of confidence in themselves and their peers. Thus, learners' uniqueness such as their different personalities and anxiety levels should also be taken into account.

Secondly, on the subject of instructors' feedback, all the participants in Martin and Valdivia (2017)'s study valued it the most and followed it by feedback from themselves and classmates, which contradict Gleason and Suvorov (2012) showing the preference for peer feedback over instructor feedback. This result is in accord with previous research indicating that instructors were considered to be learners' prime source of knowledge, so the feedback provided by them was deemed to be more reliable (Van den Boom et al., 2007).

Thirdly, as for the feedback given by automated computer systems, it can serve as an additional learning resource that monitors learners' input and output while providing immediate and individualized feedback (Fang et al., 2021;Gu et al., 2021). Ahn and Lee (2016) analyzed the user experience of a mobile-based learning system that provides timely feedback for improving speaking proficiency. The result supports prior research that appraised this system in enhancing the spoken grammar of 29 Dutch learners (de Vries et al., 2015). They stated that the system afforded a sense of collaboration for learners which is indispensable for accessing spoken output. Moreover, the research to date has identified several virtues of using computer systems to offer feedback as follows: 1) it supplies constant and intensive feedback (de Vries et al., 2015); 2) it could be controlled by learners in terms of the amount and type (Heift, 2004); 3) it is able to focus on both holistic evaluations and specific linguistic phenomena (Gu et al., 2021).

\section{Task Type}

The task is defined as a meaning-oriented material that requires learners to use the target language in order to accomplish a teaching goal (Bygate et al., 2013). On the word of Long (2000), tasks were regarded as an ideal platform for L2 teaching and learning, since the CF provided at the post-task stage drives learners attention to both forms and meanings. Task-related characters were often investigated as leading relational variables that moderate the links between feedback and L2 development, which highlights the significance of exploring the role of task type (Révész, 2009). According to Ellis (2009), there are two types of tasks, i.e., unfocused (designed for learners to use language in general communicatively) and focused tasks (designed for learners to communicate using some specific linguistic features such as certain grammatical structures). It is apparent from Table 2 that more than two-thirds of the selected articles utilized unfocused tasks (69\%), while $38 \%$ of the studies employed focused tasks.

On the subject of focused tasks, Sagarra and Abbuhl (2013) studied how computer-delivered recasts in the absence of meaning-focused interaction affected the accuracy of Spanish noun-adjective agreement in learners' spoken language. The results showed that recasts led to gains of the target feature. A possible explanation for is outcome may be the models of target structures provided by recasts could profit learners (Leeman, 2003). In a similar vein, de Vries et al. (2015) found prompt (without giving target structure) made no difference in learners' improvements of the target structure -- inversion of subject and verb in Dutch, which would further prove the importance of affording the target feature in CF (i.e., recasts) to facilitate L2 grammar learning. Another plausible reason for this result may be the complexity of the target structure which might benefit more from implicit feedback such as recasts (Goo \& Mackey, 2013). The inversion in L2 Dutch occurs even in advanced learners due to its difficulty (Blom \& de Korte, 2011). Moreover, this result reflects that of Rassaei (2019) who found that partial recast would promote target-like modified output effectually. While concerning the unfocused task, feedback mainly concentrated on general speaking proficiency, in terms of fluency, accuracy, pronunciation, and comprehension (Fang et al., 2021;Wu \& Miller, 2020). In comparison, feedback given in unfocused tasks was found to address learners' oral errors more frequently than in focused tasks (Gurzynski-Weiss \& Révész, 2012).

\section{CMF as an Internal Process}

Table 4 demonstrates the individual factors relate to CMF, i.e., individual differences, proficiency level, and L1 background. 
TABLE 4

INDIVIDUAL FACTORS

\begin{tabular}{|l|l|l|}
\hline Study & Individual differences & Proficiency level \\
\hline Ahn and Lee (2016) & N/A & N/A \\
\hline Andújar-Vaca and Cruz-Martínez (2017) & N/A & Intermediate \\
\hline Bryfonski and Ma (2020) & N/A & Beginner \& Upper-intermediate \\
\hline de Vries et al. (2015) & N/A & Pre-intermediate \& Intermediate \\
\hline de Vries et al. (2016) & N/A & Beginners \& Pre-intermediate \\
\hline Ebadijalal and Yousofi (2021) & Anxiety & Intermediate \\
\hline Fang et al. (2021) & N/A & Pre-intermediate \\
\hline Gleason and Suvorov (2012) & Potivation & N/A \\
\hline Gu et al. (2021) & NA & Intermediate \\
\hline Martin and Valdivia (2017) & Anxiety & Intermediate \\
\hline Rassaei (2017) & N/A & Intermediate \\
\hline Rassaei (2019) & N/A & N/A \\
\hline Sagarra and Abbuhl (2013) & Working memory & Upper-intermediate \\
\hline Wu and Miller (2020) & N/A & Advanced \\
\hline Yang et al. (2012) & Motivation & Beginner \& Pre-intermediate \\
\hline Yu et al. (2016) & N/A & \\
\hline
\end{tabular}

\section{Individual Differences}

Thus far, research has shown that CMF effectiveness is constrained by individual learner characteristics: 1) learners' abilities such as working memory (WM) capacity (Sagarra \& Abbuhl, 2013), 2) learners' propensities including foreign language anxiety (Ebadijalal \& Yousofi, 2021;Martin \& Valdivia, 2017), and learners' motivation (Gleason \& Suvorov, 2012; Yang et al., 2012). As exhibited by Table 4, anxiety and motivation particularly come to the forefront of the research agenda in the recent decade (13\%) in comparison with WM (6\%).

Firstly, working memory is broadly defined as the impermanent storage and manipulation of information that is essential for carrying out complex cognitive tasks (Baddeley, 2007), which can also be applied to SLA (Hasegawa et al., 2002). WM has been demonstrated to impact the noticing of interactional recasts (Egi et al., 2002;Sagarra, 2007). In line with Mackey et al. (2010), empirical evidence suggested that WM was positively associated with speaking performance in the groups that received oral computer-delivered recasts (Sagarra \& Abbuhl, 2013). In particular, learners with higher WM spans produced more accurate utterances regarding the target structure than the lower WM span learners.

Secondly, anxiety was demonstrated to have a disruptive influence on L2 acquisition in general, especially for L2 speaking (Chou, 2018;Zhang, 2019) and L2 speaking in particular (Bashori et al., 2020). Online classes may serve to mitigate anxiety by providing CMF as well as enabling learners to have more time to process input and plan output (Baralt \& Gurzynski-Weiss, 2011). Ebadijalal and Yousofi (2021) compared the effect of L1 CMF and L2 CMF on speaking performance and anxiety of $32 \mathrm{EFL}$ learners from Iran. Although participants in both groups appreciated CMF's beneficial role in diminishing anxiety, only L1 CMF led to a statistically significant reduction of anxiety at the end of the experiment. The results verified that CMF might not exert a direct impact on lowering anxiety, the language used in CMF also matters. This finding deviates from that of Martin and Valdivia (2017), reporting support towards the provision of $\mathrm{CF}$ in oral tasks regardless of participants anxiety level because CF would evoke a positive recognition of the work and make learners feel more at ease, which in turn lower learners' anxiety (Tseng \& Tsai, 2007).

Thirdly, motivation accounts for people's behaviour, the endeavor one makes, the last of willingness to sustain this activity (Dörnyei, 2002). Depending on the learner's attitudes towards the community of the target language, Gardner and Lambert (1959) classified motivation into two kinds: 1) integrative motivation (learning the target language for communication); 2) instrumental motivation (learning the target language for pragmatic and utilitarian benefits). Gleason and Suvorov (2012) examined the influence of CALL with CMF in fostering L2 learners' motivation. The majority of learners showed both integrative and instrumental motivation, who claimed to use English in the future for professional goals as well as personal communication purposes. Additionally, CALL where CMF was found to be efficient in improving learners' L2 confidence and affording opportunities to practice the target language. These results agree with the findings of Yang et al. (2012), in which CMF offered a sense of accomplishment. Since motivation positively correlates with achievement, the sense of accomplishment would further strengthen learners' motivation (Huang, 2004). The motivation type improved in Yang et al. (2012) was the integrative motivation with a highlyregarded communicative aim, whereas Gleason and Suvorov (2012) illustrated the increment in both integrative and instrumental motivation. This inconsistency may be due to the different linguistic focuses in these two studies: Yang et al. (2012) provided elicit correction on pronunciation and vocabulary, while Gleason and Suvorov (2012) focused more on fluency and speaking skills, which are more required in the professional field.

\section{Proficiency Level}

This review categorized learners' proficiency levels based on the Common European Framework of Reference for Languages (CEFR) level. In total, five proficiency levels have been identified, i.e., beginners, pre-intermediate, intermediate, upper-intermediate, and advanced. Evidence suggests that there exists an interplay between the 
effectiveness of CMF and L2 proficiency (Ziegler et al., 2018). de Vries et al. (2015) analyzed the proficiency gains under two conditions: 1) learners received oral practice and immediate CF and 2) learners received only oral practice without CF. The result revealed that unlike learners with higher proficiency levels, elementary learners were unable to improve their grammatical accuracy on the target structure without CF. This is in accordance with de Vries et al. (2016), who performed a similar experiment and found that CF significantly facilitated L2 speaking for learners with little to general knowledge (0-60\%) of the target structure, and such benefit decreased as L2 proficiency increased. Taken together, these findings indicated that CMF would produce the most salient effect on lower-intermediate learners. In detail, Bryfonski and Ma (2020) demonstrated that the lower proficiency learners were better suited for more from implicit feedback (e.g., recasts) than from explicit metalinguistic feedback, which contrasts with the finding of Li (2009) that learners with little knowledge of the target structure benefited more from explicit feedback than implicit feedback. This discrepancy could be attributed to the fact that recasts present examples of target-like language form (Sagarra \& Abbuhl, 2013).

\section{Discussion AND CONCLUSION}

This systematic review has presented an overview in light of the preceding empirical studies about the effect of CMF on L2 speaking proficiency from 2012 to 2021. Rigorous and exhaustive searches found 16 studies that met the inclusion criteria. Three sets of factors that could mediate the effect were identified, i.e., linguistic, contextual, and individual factors.

The insights and implications provided by the current review are twofold. Theoretically speaking, a comprehensive framework of CMF was proposed to facilitate understanding of the factors that play a role in the CMF process from the aforementioned three theoretical perspectives. Interactions were found not only between the factors and CMF but also between the factors. For instance, on the one hand, the impact of CMF is mediated by learners' individual factors including learners' WM capacity, anxiety levels, and proficiency levels. As Yilmaz (2013) argued that prior knowledge of a target feature (proficiency level) is assumed to affect CF. On the other hand, those individual features would also interact with linguistic factors including feedback type, linguistic focus, and feedback timing. As Yoshida (2010) suggested that instructors would determine the specific type of CF based on their perceptions of learners' oral proficiency. Pedagogically speaking, instructors should take full advantage of computer or mobile devices to promote L2 oral proficiency development. They could explicitly demonstrate their feedback strategies. In this way, learners would notice the feedback more easily and learn specific features contained in those feedback strategies. After learners have a basic understanding of feedback, instructors could train them to provide peer feedback to each other, since many learners showed favourable attitudes towards peer feedback (Ebadijalal \& Yousofi, 2021;Wu \& Miller, 2020). Instructors should also be cautious when providing CMF considering learner differences in perceiving and responding to CMF. Especially in Asian EFL contexts, where learners are always sensitive and anxious, instructors should devote effort to create a more relaxed and harmonious atmosphere by providing positive and explicitly detailed feedback.

The present study has identified several suggestions for future studies. First, although CMF attracted considerable scholarly attention, tremendous research efforts were given to investigate the linguistic factors. Thus, more attention must be paid to contextual factors (e.g., grouping, treatment length) and individual learner factors (e.g., aptitude, learning style, learner beliefs, cultural background). Second, several studies have recognized the correlation between linguistic, contextual, and individual factors. Surprisingly, their interplay has still not yet been extensively examined. Further investigation and experimentation into this topic are strongly recommended. 
APPENDIX A. SUPPLEMENTARY DATA

\begin{tabular}{|c|c|c|c|c|}
\hline \multirow[t]{2}{*}{ Study } & \multirow[t]{2}{*}{ Sample size } & \multicolumn{3}{|c|}{ Participants' portfolio } \\
\hline & & Gender & Age & L2 \\
\hline Ahn and Lee (2016) & 302 & N/A & Middle school students & English \\
\hline Andújar-Vaca and Cruz-Martínez (2017) & 80 & $32 \mathrm{M} ; 48 \mathrm{~F}$ & $18-31$ & English \\
\hline Bryfonski and Ma (2020) & 41 & $18 \mathrm{M} ; 23 \mathrm{~F}$ & Mean $=39.5$ years & Chinese, Mandarin \\
\hline de Vries et al. (2015) & 29 & $11 \mathrm{M} ; 18 \mathrm{~F}$ & $22-48$ (Mean=31 years) & Dutch \\
\hline de Vries et al. (2016) & 31 & $15 \mathrm{M} ; 16 \mathrm{~F}$ & $16-62$ (Mean=28 years) & Dutch \\
\hline Ebadijalal and Yousofi (2021) & 32 & $32 \mathrm{~F}$ & $19-28$ & English \\
\hline Fang et al. (2021) & 66 & $56 \mathrm{M} ; 10 \mathrm{~F}$ & $18-20$ & English \\
\hline Gleason and Suvorov (2012) & 10 & N/A & $20-30$ (Mean=25 years) & English \\
\hline Gu et al. (2021) & 154 & N/A & N/A & English \\
\hline Martin and Valdivia (2017) & 50 & $17 \mathrm{M} ; 33 \mathrm{~F}$ & $\begin{array}{lrr}\begin{array}{l}\text { Two-thirds } \\
\text { participants }\end{array} & \text { of } & \text { the } \\
\text { there } & \text { older } \\
\text { than } 25 & & \end{array}$ & English \\
\hline Rassaei (2017) & 57 & $25 \mathrm{M} ; 32 \mathrm{~F}$ & $18-33$ & English \\
\hline Rassaei (2019) & 70 & $29 \mathrm{M} ; 41 \mathrm{~F}$ & $22-33$ & English \\
\hline Sagarra and Abbuhl (2013) & 218 & N/A & $\begin{array}{l}\text { First - semester Spanish } \\
\text { students }\end{array}$ & Spanish \\
\hline Wu and Miller (2020) & 25 & $10 \mathrm{M} ; 15 \mathrm{~F}$ & $18-22$ & English \\
\hline Yang et al. (2012) & 90 & N/A & N/A & English \\
\hline Yu et al. (2016) & 159 & N/A & N/A & English \\
\hline
\end{tabular}

Note. $M$ stands for males, $F$ stands for females

\section{REFERENCES}

[1] AbuSeileek, A., \& Abualsha'r, A. (2014). Using peer computer-mediated corrective feedback to support EFL learners' writing. Language Learning \& Technology, 18(1), 76-95. https://doi.org/10.1111/jcal.12004

[2] Ahn, T. Y., \& Lee, S. M. (2016). User experience of a mobile speaking application with automatic speech recognition for EFL learning. British Journal of Educational Technology, 47(4), 778-786. https://doi.org/10.1111/bjet.12354

[3] Andújar-Vaca, A., \& Cruz-Martínez, M.-S. (2017). Mobile instant messaging: WhatsApp and its potential to develop oral skills. Comunicar. Media Education Research Journal, 25(1). https://doi.org/10.3916/C50-2017-04

[4] Baddeley, A. (2007). Working memory, thought, and action. Oxford University Press.

[5] Bahari, A. (2021). Computer - mediated feedback for L2 learners: Challenges versus affordances. Journal of Computer Assisted Learning, 37(1), 24-38. https://doi.org/10.1111/jcal.12481

[6] Baralt, M., \& Gurzynski-Weiss, L. (2011). Comparing learners' state anxiety during task-based interaction in computermediated and face-to-face communication. Language Teaching Research, 15(2), 201-229. https://doi.org/10.1177/0265532210388717

[7] Bashori, M., van Hout, R., Strik, H., \& Cucchiarini, C. (2020). Web-based language learning and speaking anxiety. Computer Assisted Language Learning, 1-32. https://doi.org/10.1080/09588221.2020.1770293

[8] Bitchener, J., \& Ferris, D. R. (2012). Written corrective feedback in second language acquisition and writing. Routledge. https://doi.org/10.1080/09588221.2020.1770293

[9] Blom, E., \& de Korte, S. (2011). Dummy auxiliaries in child and adult second language acquisition of Dutch. Lingua, 121(5), 906-919. https://doi.org/10.1016/j.lingua.2010.12.004

[10] Bryfonski, L., \& Ma, X. (2020). Effects of implicit versus explicit corrective feedback on mandarin tone acquisition in a SCMC learning environment. Studies in Second Language Acquisition, 42(1), 61-88. https://doi.org/10.1017/S0272263119000317

[11] Bygate, M., Skehan, P., \& Swain, M. (2013). Researching pedagogic tasks: Second language learning, teaching, and testing. Routledge.

[12] Carless, D. (2016). Feedback as dialogue. In M. Peters (Ed.), Encyclopedia of Educational Philosophy and Theory (pp. 1-6). Springer Singapore. https://doi.org/10.1007/978-981-287-532-7_389-1

[13] Chou, M. H. (2018). Speaking anxiety and strategy use for learning English as a foreign language in full and partial English - medium instruction contexts. Tesol Quarterly, 52(3), 611-633. https://doi.org/10.1002/tesq.455

[14] Cornillie, F., Clarebout, G., \& Desmet, P. (2012). Between learning and playing? Exploring learners' perceptions of corrective feedback in an immersive game for English pragmatics. ReCALL, 24(3), 257-278. https://doi.org/10.1017/S0958344012000146

[15] Penning de Vries, B., Cucchiarini, C., Bodnar, S., Strik, H., \& van Hout, R. (2015). Spoken grammar practice and feedback in an ASR-based CALL system. Computer Assisted Language Learning, 28(6), 550-576. https://doi.org/10.1080/09588221.2014.889713

[16] Penning de Vries, B., Cucchiarini, C., Bodnar, S., Strik, H., \& van Hout, R. (2016). Effect of corrective feedback for learning verb second. International Review of Applied Linguistics in Language Teaching, 54(4), 347-386. https://doi.org/10.1515/iral2016-0121

[17] Dörnyei, Z. (2002). The motivational basis of language learning tasks. In P. Robinson (Ed.), Individual Differences and Instructed Language Learning (Vol. 2, pp. 137-158). John Benjamins Publishing Company. https://doi.org/10.1075/11lt.2.10dor

[18] Ebadijalal, M., \& Yousofi, N. (2021). The impact of mobile-assisted peer feedback on EFL learners' speaking performance and anxiety: Does language make a difference? The Language Learning Journal, 1-19. https://doi.org/10.1080/09571736.2021.1957990

[19] Egi, T., Fujii, A., \& Tatsumi, T. (2002). Individual differences in working memory, noticing of interactional feedback and L2 development. John Benjamins Publishing Company. https://doi.org/10.1075/1llt.2.12mac 
[20] Ellis, R. (2009). Task-based language teaching: Sorting out the misunderstandings. International Journal of Applied Linguistics, 19(3), 221-246. https://doi.org/10.1111/j.1473-4192.2009.00231.x

[21] Ellis, R. (2010a). Cognitive, social, and psychological dimensions of corrective feedback. Sociocognitive perspectives on language use and language learning, 151-165.

[22] Ellis, R. (2010b). Epilogue: A framework for investigating oral and written corrective feedback. Studies in Second Language Acquisition, 32(2), 335-349. https://doi.org/10.1017/S0272263109990544

[23] Fang, W.-C., Yeh, H.-C., Luo, B.-R., \& Chen, N.-S. (2021). Effects of mobile-supported task-based language teaching on EFL students' linguistic achievement and conversational interaction. ReCALL, 33(1), 71-87. https://doi.org/10.1017/S0958344020000208

[24] Gardner, R. C., \& Lambert, W. E. (1959). Motivational variables in second-language acquisition. Canadian Journal of Psychology, 13(4), 266. https://doi.org/10.1037/h0083787

[25] Gašević, D., Dawson, S., Rogers, T., \& Gasevic, D. (2016). Learning analytics should not promote one size fits all: The effects of instructional conditions in predicting academic success. The Internet and Higher Education, 28, 68-84. https://doi.org/10.1016/j.iheduc.2015.10.002

[26] Gleason, J., \& Suvorov, R. (2012). Learner perceptions of asynchronous oral computer-mediated communication: Proficiency and second language selves. Canadian Journal of Applied Linguistics, 15(1), 100-121.

[27] Goo, J., \& Mackey, A. (2013). The case against the case against recasts. Studies in Second Language Acquisition, 35(1), $127-$ 165. https://doi.org/10.1017/S0272263112000708

[28] Goodman, J. S., Wood, R. E., \& Hendrickx, M. (2004). Feedback specificity, exploration, and learning. Journal of Applied Psychology, 89(2), 248. https://doi.org/10.1037/0021-9010.89.2.248

[29] Gu, L., Davis, L., Tao, J., \& Zechner, K. (2021). Using spoken language technology for generating feedback to prepare for the TOEFL iBT® test: A user perception study. Assessment in Education: Principles, Policy \& Practice, 28(1), 58-76. https://doi.org/10.1080/0969594X.2020.1735995

[30] Guadagnoli, M. A., Dornier, L. A., \& Tandy, R. D. (1996). Optimal length for summary knowledge of results: the influence of task-related experience and complexity. Research Quarterly for Exercise and Sport 67(2), 239-248. https://doi.org/10.1080/02701367.1996.10607950

[31] Gurzynski-Weiss, L., \& Révész, A. (2012). Tasks, teacher feedback, and learner modified output in naturally occurring classroom interaction. Language Learning, 62(3), 851-879. https://doi.org/10.1111/j.1467-9922.2012.00716.x

[32] Hasegawa, M., Carpenter, P. A., \& Just, M. A. (2002). An fMRI study of bilingual sentence comprehension and workload. Neuroimage, 15(3), 647-660. https://doi.org/10.1006/nimg.2001.1001

[33] Hattie, J., \& Timperley, H. (2007). The power of feedback. Review of Educational Research, 77(1), 81-112. https://doi.org/10.3102/003465430298487

[34] Heift, T. (2004). Corrective feedback and learner uptake in CALL. ReCALL, 16(2), $416-431$. https://doi.org/10.1017/S0958344004001120

[35] Heift, T., \& Rimrott, A. (2008). Learner responses to corrective feedback for spelling errors in CALL. System, 36(2), 196-213. https://doi.org/10.1016/j.system.2007.09.007

[36] Herring, S. C. (1996). Computer-mediated communication: Linguistic, social, and cross-cultural perspectives. John Benjamins Publishing. https://doi.org/10.1016/j.system.2007.09.007

[37] Huang, H. (2004). The relationship between learning motivation and speaking anxiety among EFL non-English major freshmen in Taiwan [Unpublished master's thesis]. Chaoyang University of Technology.

[38] Hughes, R., \& Reed, B. S. (2016). Teaching and researching speaking. Routledge.

[39] Kato, F., Spring, R., \& Mori, C. (2016). Mutually beneficial foreign language learning: Creating meaningful interactions through video-synchronous computer-mediated communication. Foreign Language Annals, 49(2), 355-366. https://doi.org/10.1111/flan.12195

[40] Kelm, O. R. (1992). The use of synchronous computer networks in second language instruction: A preliminary report. Foreign Language Annals, 25(5), 441-454. https://doi.org/10.1111/j.1944-9720.1992.tb01127.x

[41] Kern, R. G. (1995). Restructuring classroom interaction with networked computers: Effects on quantity and characteristics of language production. The Modern Language Journal, 79(4), 457-476. https://doi.org/10.1111/j.1540-4781.1995.tb05445.x

[42] Kim, H. Y. (2014). Learning opportunities in synchronous computer-mediated communication and face-to-face interaction. Computer Assisted Language Learning, 27(1), 26-43. https://doi.org/10.1080/09588221.2012.692386

[43] Leeman, J. (2003). Recasts and second language development: Beyond negative evidence. Studies in Second Language Acquisition, 25(1), 37-63. https://doi.org/10.1017/S0272263103000020

[44] Li, S. (2009). The differential effects of implicit and explicit feedback on second language (L2) learners at different proficiency levels. Applied Language Learning, 19(1), 53-79.

[45] Lochtman, K. (2002). Oral corrective feedback in the foreign language classroom: How it affects interaction in analytic foreign language teaching. International Journal of Educational Research, 37(3-4), 271-283. https://doi.org/10.1016/S08830355(03)00005-3

[46] Long, M. (1996). The role of the linguistic environment in second language acquisition. In W. C. Ritchie \& B. K. Bahtia (Eds.), Handbook of second language acquisition (pp. 413-468). New York: Academic Press. https://doi.org/10.1016/B978012589042-7/50015-3

[47] Long, M. H. (2000). Focus on form in task-based language teaching. In R. Lambert \& E. Shohamy (Eds.), Language Policy and Pedagogy: Essays in honor of A. Ronald Walton (pp. 35-49). John Benjamins Publishing Company.

[48] Lyster, R., \& Ranta, L. (1997). Corrective feedback and learner uptake: Negotiation of form in communicative classrooms. Studies in Second language acquisition, 37-66. https://www.jstor.org/stable/44488666

[49] Lyster, R., \& Saito, K. (2010). Oral feedback in classroom SLA: A meta-analysis. Studies in Second Language Acquisition, 32(2), 265-302. https://doi.org/10.1017/S0272263109990520 
[50] Lyster, R., Saito, K., \& Sato, M. (2013). Oral corrective feedback in second language classrooms. Language Teaching, 46(1), 1-40. https://doi.org/10.1017/S0261444812000365

[51] Mackey, A., Adams, R., Stafford, C., \& Winke, P. (2010). Exploring the relationship between modified output and working memory capacity. Language Learning, 60(3), 501-533. https://doi.org/10.1111/j.1467-9922.2010.00565.x

[52] Mackey, A., Gass, S., \& McDonough, K. (2000). How do learners perceive interactional feedback? Studies in Second Language Acquisition, 22(4), 471-497. https://doi.org/10.1017/S0272263100004010

[53] Mackey, A., \& Philp, J. (1998). Conversational interaction and second language development: Recasts, responses, and red herrings? The Modern Language Journal, 82(3), 338-356. https://doi.org/10.1111/j.1540-4781.1998.tb01211.x

[54] Martin, S., \& Valdivia, I. M. A. (2017). Students' feedback beliefs and anxiety in online foreign language oral tasks. International Journal of Educational Technology in Higher Education, 14(1), 1-15. https://doi.org/10.1186/s41239-017-0056-z

[55] Pawlak, M. (2014). Investigating learner engagement with oral corrective feedback: aims, methodology, outcomes. In A. Łyda \& K. Szcześniak (Eds.), Awareness in Action: The Role of Consciousness in Language Acquisition (pp. 69-84). Springer International Publishing. https://doi.org/10.1007/978-3-319-00461-7_5

[56] Rassaei, E. (2017). Video chat vs. face-to-face recasts, learners' interpretations and L2 development: A case of Persian EFL learners. Computer Assisted Language Learning, 30(1-2), 133-148. https://doi.org/10.1080/09588221.2016.1275702

[57] Rassaei, E. (2019). Recasts during mobile-mediated audio and video interactions: learners' responses, their interpretations, and the development of English articles. Computer Assisted Language Learning, 1-27. https://doi.org/10.1080/09588221.2019.1671461

[58] Révész, A. (2009). Task complexity, focus on form, and second language development. Studies in Second Language Acquisition, 31(3), 437-470. https://doi.org/10.1017/S0272263109090366

[59] Sadler, D. R. (1989). Formative assessment and the design of instructional systems. Instructional Science, 18(2), 119-144. https://doi.org/10.1007/BF00117714

[60] Sagarra, N. (2007). Working Memory and L2 Processing of Redundant Grammatical Forms. In Z. Han (Ed.), Understanding Second Language Process (pp. 133-147). Multilingual Matters. https://doi.org/10.21832/9781847690159-009

[61] Sagarra, N., \& Abbuhl, R. (2013). Optimizing the noticing of recasts via computer-delivered feedback: Evidence that oral input enhancement and working memory help second language learning. The Modern Language Journal, 97(1), 196-216. https://doi.org/10.1111/j.1540-4781.2013.01427.x

[62] Schmidt, R. (1994). Deconstructing consciousness in search of useful definitions for applied linguistics. Consciousness in second language learning, 11, 237-326.

[63] Schmidt, R. W. (1990). The Role of Consciousness in Second Language Learning. Applied Linguistics, 11(2), 129-158. https://doi.org/10.1093/applin/11.2.129

[64] Sheen, Y. (2008). Recasts, language anxiety, modified output, and L2 learning. Language Learning, 58(4), 835-874. https://doi.org/10.1111/j.1467-9922.2008.00480.x

[65] Sheen, Y., \& Ellis, R. (2011). Corrective feedback in language teaching. In E. Hinkel (Ed.), Handbook of Research in Second Language Teaching and Learning (pp. 593-610). Routledge. https://doi.org/10.4324/9780203836507.ch36

[66] Shin, J. (2020). A meta-analysis of the relationship between working memory and second language reading comprehension: Does task type matter? Applied Psycholinguistics, 41(4), 873-900. https://doi.org/10.1017/S0142716420000272

[67] Shintani, N. (2016). The effects of computer-mediated synchronous and asynchronous direct corrective feedback on writing: a case study. Computer Assisted Language Learning, 29(3), 517-538. https://doi.org/10.1080/09588221.2014.993400

[68] Smith, B., Alvarez-Torres, M. a. J., \& Zhao, Y. (2003). Features of CMC technologies and their impact on language learners' online interaction. Computers in Human Behavior, 19(6), 703-729. https://doi.org/10.1080/09588221.2014.993400

[69] Smits, M. H., Boon, J., Sluijsmans, D. M., \& Van Gog, T. (2008). Content and timing of feedback in a web-based learning environment: Effects on learning as a function of prior knowledge. Interactive Learning Environments, 16(2), 183-193. https://doi.org/10.1080/10494820701365952

[70] Swain, M. (1993). The output hypothesis: Just speaking and writing aren't enough. Canadian modern language review, 50(1), 158-164. https://doi.org/10.3138/cmlr.50.1.158

[71] Tabrizi, A. N. (2021). The Effect of Computer-Mediated Text-Based and Audio-Based Corrective Feedback On the Development of Writing Accuracy of Iranian EFL Learners. Turkish Journal of Computer and Mathematics Education (TURCOMAT), 12(13), 4675-4692.

[72] Tseng, S.-C., \& Tsai, C.-C. (2007). On-line peer assessment and the role of the peer feedback: A study of high school computer course. Computers \& Education, 49(4), 1161-1174. https://doi.org/10.1016/j.compedu.2006.01.007

[73] Uzum, B. (2011). Who gains more?: A case of motivation and corrective feedback in ESL classes. In J. Perren, K. Losey, D. O. Perren, \& A. Piippo (Eds.), Transforming learning: Teaching, advocacy, and ESL at the crossroads. Selected proceedings of 2009-2010 MITESOL conferences (pp. 19-39). Eastern Michigan University.

[74] Van den Boom, G., Paas, F., \& Van Merrienboer, J. J. (2007). Effects of elicited reflections combined with tutor or peer feedback on self-regulated learning and learning outcomes. Learning and Instruction, 17(5), 532-548. https://doi.org/10.1016/j.learninstruc.2007.09.003

[75] van Ginkel, S., Gulikers, J., Biemans, H., \& Mulder, M. (2017). The impact of the feedback source on developing oral presentation competence. Studies in Higher Education, 42(9), 1671-1685. https://doi.org/10.1080/03075079.2015.1117064

[76] Wu, J. G., \& Miller, L. (2019). Raising native cultural awareness through WeChat: a case study with Chinese EFL students. Computer Assisted Language Learning, 1-31. https://doi.org/10.1080/09588221.2019.1629962

[77] Wu, J. G., \& Miller, L. (2020). Improving English learners' speaking through mobile-assisted peer feedback. RELC journal, 5l(1), 168-178. https://doi.org/10.1080/09588221.2019.1629962

[78] Yang, Y. T. C., Gamble, J., \& Tang, S. Y. S. (2012). Voice over instant messaging as a tool for enhancing the oral proficiency and motivation of English-as-a-foreign-language learners. British Journal of Educational Technology, 43(3), 448-464.

[79] Yilmaz, Y. (2013). The relative effectiveness of mixed, explicit and implicit feedback in the acquisition of English articles. System, 41(3), 691-705. https://doi.org/10.1016/j.system.2013.07.020 
[80] Yoshida, R. (2010). How do teachers and learners perceive corrective feedback in the Japanese language classroom? The Modern Language Journal, 94(2), 293-314. https://doi.org/10.1111/j.1540-4781.2010.01022.x

[81] Young, S. S.-C., \& Wang, Y.-H. (2014). The game embedded CALL system to facilitate English vocabulary acquisition and pronunciation. Journal of Educational Technology \& Society, 17(3), 239-251.

[82] Yu, S., \& Lee, I. (2016). Peer feedback in second language writing (2005-2014). Language Teaching, 49(4), $461-493$. https://doi.org/10.1017/S0261444816000161

[83] Yu, S., Wang, B., \& Teo, T. (2018). Understanding linguistic, individual and contextual factors in oral feedback research: A review of empirical studies in L2 classrooms. Educational Research Review, 24, 181-192. https://doi.org/10.1016/j.edurev.2018.06.001

[84] Zhang, X. (2019). Foreign language anxiety and foreign language performance: A meta-analysis. The Modern Language Journal, 103(4), 763-781. https://doi.org/10.1111/modl.12590

[85] Ziegler, N. (2016). Synchronous computer-mediated communication and interaction: A meta-analysis. Studies in Second Language Acquisition, 38(3), 553-586. https://doi.org/10.1017/S027226311500025X

[86] Ziegler, N., Bryfonski, L., Malovrh, P., \& Benati, A. (2018). Interaction-driven L2 learning: Advanced learners. In P. Malovrh \& A. Benati (Eds.), The Handbook of Advanced Proficiency in Second Language Acquisition (pp. 94-113). Wiley Blackwell.

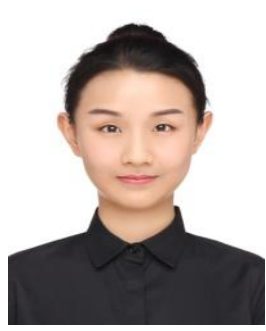

Wenrui Zhang received her M.A. degree from The Chinese University of Hong Kong, in July 2020. She is currently pursuing the M.Phil. degree with the Department of English, The Chinese University of Hong Kong. Her research interests include second language acquisition, digital literacies, second language teaching. She works as an English teacher at a secondary school. Ms. Zhang is also a member of The Hong Kong Association for Applied Linguistics (HAAL) and Hong Kong Federation of Education Workers. 